\title{
Developing and applying a socio-ecological model to the promotion of healthy eating in the school
}

\author{
Nick Townsend* and Charlie Foster \\ British Heart Foundation Health Promotion Research Group, University of Oxford and National Obesity \\ Observatory, BHF HPRG, Old Road Campus, Headington, Oxford OX3 7LF, UK
}

Submitted 22 November 2010: Accepted 9 September 2011: First published online 13 October 2011

\begin{abstract}
Objective: To develop and apply a socio-ecological model (SEM) for healthy eating in school students, to better understand the association between factors at different levels of the SEM and pupils' dietary choices.

Design: Student-level data, collected through anonymised questionnaires, included reported dietary choices and correlates to these; data on school approaches to food were collected through postal surveys. We used multilevel analysis to study the association of each level of the SEM on student dietary choice while controlling for factors found at other levels.

Setting: Data were collected from secondary schools in Wales that were a part of the 2005/2006 Health Behaviour in School-aged Children (HBSC) study.

Subjects: The final sample for analysis included data from 6693 students aged 11-16 years and 289 teachers from sixty-four secondary schools in Wales.

Results: Student interpersonal factors, an individual's social environment, had a greater association with the dietary choices students made for lunch than student intrapersonal characteristics, those that reside within the person, which were found to have a greater association with the dietary choices made outside school. School organisational factors, such as rules and policies, had a greater association with whether students ate unhealthy foods, whereas the community nature of the school had a greater association with the choosing of healthy foods.

Conclusions: Using the SEM and multilevel analysis allowed us to study how factors were associated with the choice of different foods at different times of the day by students. Interventions can use an SEM to target specific correlates and change health outcomes in the school.
\end{abstract}

\author{
Keywords \\ Schools \\ Healthy eating \\ Socio-ecological model \\ Adolescents and children
}

Schools are a popular area for health promotion for young people and adolescents as they can target a large population in an economically efficient manner ${ }^{(1)}$. As children spend more time in schools than any other environment outside the home ${ }^{(2,3)}$, they provide unparalleled access through continuous and intensive contact.

Current school health promotion approaches, developed in light of the failure of traditional didactic approaches of health education, are implemented through the 'settings' approach $^{(4-8)}$. This settings approach recognises the impact the relationship between individuals and their environment has on their health ${ }^{(9)}$. This is articulated in schools through the health promoting school concept ${ }^{(10-13)}$ which has been embraced internationally as an effective method for promoting the health of children, adolescents and the wider school community ${ }^{(10,11,14,15)}$.

The conceptual base for a settings approach is the socio-ecological model (SEM) of health promotion that was advocated in the Ottawa Charter for Health Promotion ${ }^{(16)}$.
There are two key concepts of this approach: (i) behaviour affects and is affected by multiple levels of influence; and (ii) individual behaviour shapes and is shaped by the social environment (reciprocal causation). The SEM emphasises the interaction between, and interdependence of, factors within and across all levels of health behaviour, recognising that most public health challenges are too complex to be adequately understood and addressed from single-level analyses ${ }^{(17)}$. In doing so it demands that individuals are not viewed in isolation from the larger social units in which they live their lives, pointing to the need to create environmental conditions that support, and promote, effective and sustainable behaviour change.

SEM for health have been adopted in dealing with many health behaviours ${ }^{(17-22)}$, including healthy eating and childhood obesity ${ }^{(23)}$, as they provide useful frameworks for achieving a better understanding of the multiple factors and barriers that impact on dietary behaviours. Although past studies have used SEM in developing 
conceptual models to investigate the impact of interventions on healthy eating ${ }^{(19,20,22,24,25)}$, as far as the authors are aware none have investigated the relative association of the different levels found in these models through multilevel analysis. Where studies have used multilevel analysis to investigate school effects on student dietary choice they have found no significant school-level variance once controlling for student-level characteristics ${ }^{(5,15,26,27)}$, suggesting that differences in student dietary choice between schools is due to the composition of the individuals who attended the schools and not the school approaches to food. These studies incorporated few school-level factors that targeted student dietary choice in their analyses, either focusing on a very small number of factors such as the availability of unhealthy snacks and drinks ${ }^{(5,26,27)}$, the availability of healthy food ${ }^{(26)}$, the distance from school to the nearest food store ${ }^{(27)}$ and whether students were allowed to leave the school grounds during lunch ${ }^{(5)}$, or by considering general school-level characteristics ${ }^{(15)}$ that are not directly related to dietary choice. In doing so it was not possible for the studies to consider the multifactorial approach to the promotion of healthy eating as described in the SEM and promoted through the whole school approach to healthy eating developed from a settings perspective ${ }^{(28)}$.

Within the present paper we develop an SEM that considers the multiple levels of influence on the promotion of healthy eating in the school as well as the interaction between these levels. We then apply this model to the multilevel analysis of the promotion of healthy eating within secondary schools in Wales to study how factors at different levels of the SEM are associated with dietary behaviour of students, the use of the SEM informing our data collection, analysis and understanding of healthy eating within schools.

\section{Methods}

\section{Developing a socio-ecological model}

We developed an SEM for health promotion in the school through adapting previous models. Our model was based largely on McLeroy and colleagues, ${ }^{(29)}$ variation of Brofenbrenner's ${ }^{(30,31)}$ ecological model that consisted of five levels of influence for health-related behaviours and conditions. We also reviewed other frameworks such as
Dahlgren and Whiteheads'(32) 'main determinants of health from a socio-ecological perspective' and Barton and Grants' health map ${ }^{(33)}$ that represented the determinants of health behaviours at the different system levels that the SEM describes, as well as suggesting complex interconnections among these determinants.

Within the SEM developed for the present study we included six levels of influence, encompassing both student- and school-level influences (Table 1), which should be considered when developing health promotion approaches within schools or when investigating the health behaviour of students.

By applying this SEM to the promotion of healthy eating within schools, we were able to identify the important aspects that influence healthy eating and the promotion of healthy dietary choice. This subsequently informed both the collection of data and the analysis. The SEM was used to target an investigation into the influences on student dietary choice in schools by providing areas to examine in case studies completed in two schools in Wales and through an extensive review of the literature for each level of the SEM. Data collection in the case studies involved focus groups with pupils, semi-structured interviews with staff and observations of the school food environment; some trialling of dietary recall questions was also carried out during case studies to examine if students related to eating foods included in the questions. Data were then collected on factors identified in this preliminary research in the main data collection, with variables describing these factors included in the final analyses.

\section{Main data collection}

Data at the student level were collected from school students aged 11-16 years through the Wales sample of the 2005/2006 Health Behaviour in School-aged Children (HBSC) study. The student survey was administered between January and April 2006, as a self-completion in-school questionnaire to all sampled students attending school on the day of the survey; absent students were not followed up. Sampling and data collection protocol for the 2005/2006 HBSC followed that for the 2001/2002 survey $^{(34)}$.

School-level data on the school approaches to promote healthy eating were collected through postal questionnaires

Table 1 A socio-ecological framework for the investigation of the promotion of health behaviour in schools

\begin{tabular}{ll}
\hline Levels of influence & Description \\
\hline Student demographic & $\begin{array}{c}\text { Constitutional and biologically determined factors that have been found to be associated with variations in } \\
\text { health behaviours } \\
\text { Individual characteristics that reside within the person and can influence behaviour } \\
\text { An individual's relationships and social environment that affect behaviour by providing norms, social support } \\
\text { and behaviour modelling }\end{array}$ \\
$\begin{array}{l}\text { Student intrapersonal } \\
\text { Policies, informal structures and rules in schools that may constrain or promote health } \\
\text { School organisation }\end{array}$ & $\begin{array}{c}\text { Relationships between schools and other organisations or institutions, and informal social networks within } \\
\text { schools themselves } \\
\text { Policies and legislation at a local or national level that regulate or support health promotion in schools }\end{array}$ \\
$\begin{array}{l}\text { Macro-level } \\
\text { organisation }\end{array}$ &
\end{tabular}


sent to members of teaching staff within the schools in which the HBSC study was carried out, alongside information provided by the Welsh Assembly Government. The majority of school-level variables came from pre-coded close-ended questions that provided variable categories as responses. Data collection from staff in schools aimed to achieve two or more completed questionnaires from each school, allowing modal responses of staff within the school to be used in the derivation of variables. Further details on data collection can be found elsewhere ${ }^{(28)}$.

\section{Multilevel analysis}

Multilevel analysis assists in efforts to investigate school approaches to healthy eating from the perspective of the SEM, by enabling the analysis of the relative contribution of different levels of determinants and also of their crosslevel interactions ${ }^{(2)}$. Indeed socio-ecological and multilevel approaches are recommended for research into healthy eating in schools ${ }^{(19,35)}$. Multilevel analysis allowed us to carry out analysis incorporating student- and schoollevel variables and enabled us to investigate where and how effects were occurring ${ }^{(36,37)}$.

\section{Dependent variables}

Two types of self-report dietary behaviour measure were used as dependent variables in analysis. First, summary measures of the frequency of consumption of (i) healthy and (ii) unhealthy food items; and second, measures of whether or not three different foods were eaten at lunch time. These types of dependent variables were chosen to investigate any difference in the association of factors from the various levels of the SEM for food eaten during the school day, i.e. lunch time, and that eaten throughout the whole day, including food eaten outside school.

For the frequency measures, students were asked: 'How many times a week do you usually eat...?' for two different healthy food items (fruit/vegetables) and four different unhealthy food items (cola and other soft drinks/ sweets and chocolate/crisps/chips). For each food item, there were seven possible responses ('never', 'less than once a week', 'once a week', '2-4 days a week', '5-6 days a week', 'once a day every day', 'every day more than once'). Each of the two summary measures was obtained by counting, for each student, the number of healthy $(0-2)$ or unhealthy (0-4) items reported as consumed at least daily.

For the foods eaten at lunch time, dichotomous variables were derived to indicate those students who agreed (1) or disagreed (0) that they ate the food for lunch. This was based on responses to questions which asked students to indicate their agreement with the statement: 'I eat (food) for lunch', which was asked for three food items (fruit/chips/ sweets and chocolate) on a 7-point scale. Those indicating that they 'agree very strongly', 'agree strongly' or 'agree slightly' were coded as agreeing that they ate that food item for lunch. These questions were taken from a study on adolescent food choice ${ }^{(34)}$.

\section{Analytical approach}

Two-level random effects models were run in the software MlWin $2 \cdot 1$ (Centre for Multilevel Modelling, University of Bristol, Bristol, UK) for each of the dependent variables: level one corresponded to students and included student-level variables, level two to schools and included school-level variables. These models were logistic for the three binary lunch variables and ordinal logistic for the healthy and unhealthy frequency variables. The independent variables derived from the data collection were assigned to the level of influence at which they can be found from the SEM (Table 2). In Table 2 variable values are provided in brackets. Many variables were dichotomous; those that had more complex values or construction are described in footnotes below the table. Variables in normal font were derived from the student questionnaires, variables in normal bold were derived from the teacher questionnaire, variables in italic bold were derived from information supplied by the Welsh Assembly Government, underlined variables were not included in final analyses as data were not collected on them. More information on variables and can be found elsewhere $^{(28)}$.

The percentage of school-level variance attributed to each level of the SEM for the dependent variables was calculated by presenting the difference between the residual error variances for the full model and those for the model without all variables from that level of influence from the SEM, expressed as a percentage of residual error variance of the full model ${ }^{(38)}$.

\section{Results}

In the final sample seventy schools completed the HBSC survey, with 7300 students completing the questionnaire. Of these seventy schools, sixty-four completed two or more teacher questionnaires (total $n$ 289) and thus could be included in the analysis. This resulted in $90 \%$ of the state schools from the HBSC sample being retained for the analysis, equating to $26 \%$ of the state schools in Wales, with a final sample for analysis involving the school-level variables of 6693 students in sixty-four schools in Wales.

There were no significant differences between schools that did and did not return two or more questionnaires in terms of location, language medium of school, number of students in the school and the proportion of students eligible for free school meals. Wald tests indicated a significant variation at the school level once controlling for all student-level variables, indicating the data were applicable for multilevel analysis (Table 3).

As the SEM describes, interactions can occur within the same level and across the levels. Thus many of the variables could be assigned to, and interact with, a number of levels. For example, although the "number of four main 
Table 2 Summary of factors included in the analysis, showing variables of influence on student dietary choice in relation to level within the socio-ecological model applied to our data collection

\begin{tabular}{|c|c|c|c|c|c|}
\hline Student demographic & Student intrapersonal & Student interpersonal & School organisation & School community & Macro-level organisation \\
\hline Sex (boy/girl) & Hours of TV viewing per & Family setup (both parents/ & School type (state funded/fee & Number of students on & \multirow[t]{2}{*}{$\begin{array}{l}\text { Number of phases } \\
\text { completed in WNHSS } \|\end{array}$} \\
\hline Age (year group 7-11) & On a diet (yes/no) & $\begin{array}{l}\text { Family Affluence Scales } \\
\text { (SES) }\end{array}$ & $\begin{array}{l}\text { School has healthy eating policy } \\
\text { (no policy/informal policyl } \\
\text { written policy) }\end{array}$ & $\begin{array}{l}\text { SES percentage of } \\
\text { students on free } \\
\text { school meals }\end{array}$ & \\
\hline \multirow{5}{*}{ Ethnicity } & $\begin{array}{l}\text { Number of days spend time } \\
\text { after school with friends } \\
(0-7 \text { d) }\end{array}$ & $\begin{array}{l}\text { What friends think student } \\
\text { should eat for luncht }\end{array}$ & $\begin{array}{l}\text { Quality of information given on } \\
\text { healthy eating (good/not good) }\end{array}$ & $\begin{array}{l}\text { Shop close to school that } \\
\text { students can buy food } \\
\text { from (yes/no) }\end{array}$ & \multirow{5}{*}{$\begin{array}{l}\text { Local Authority approaches } \\
\text { to school food }\end{array}$} \\
\hline & $\begin{array}{l}\text { School lunch behaviour } \\
\text { (school lunch/packed lunch/ } \\
\text { school snack/leave school/ } \\
\text { go home/no lunch) }\end{array}$ & Family dietary choice & $\begin{array}{l}\text { School provides free samples of } \\
\text { healthy food (yes/no) }\end{array}$ & $\begin{array}{l}\frac{\text { Links to parents to }}{\text { generate consistent }} \\
\frac{\text { healthy eating messages }}{\text { between school and }} \\
\text { home }\end{array}$ & \\
\hline & $\begin{array}{l}\text { Is the individual health } \\
\text { conscioust }\end{array}$ & & $\begin{array}{l}\text { Healthiness of school food } \\
\text { complements education (yes/not } \\
\text { sure/no) }\end{array}$ & & \\
\hline & $\begin{array}{l}\text { Is the individual concerned } \\
\text { about eating healthilyt }\end{array}$ & & Snack vending in school (yes/no) & & \\
\hline & Knowledge and skill & & Length of lunch break ( $\mathrm{min}$ ) & & \\
\hline
\end{tabular}

TV, television; SES, socio-economic status; WNHSS, Welsh Network of Healthy School Schemes; HBSC, Health Behaviour in School-aged Children.

+Variables used a 7-point Likert scale from 'agree very strongly' to 'disagree very strongly'. For interpersonal variables students were asked 'Do you agree that your family/friend think you should eat....?' or '...your friends eat...?' for each food measured in the dependent variables.

fEngagement with school variable is a four-level composite variable derived from three questions in the HBSC questionnaire ${ }^{(40)}$. The higher the score, the greater the engagement with school.

\$Family Affluence Scale is a four-item composite score to judge individual SES ${ }^{(38,39)}$

||Within the WNHSS schools complete phases in which they implement a number of health promoting actions. Once schools are adjudged to have completed one phase, through inspection by outside parties, they move on to the next ${ }^{(41)}$. 
Table 3 Student and school sample sizes for final models and significant school-level variation once controlling for student-level factors for each dependent variable

\begin{tabular}{|c|c|c|c|c|c|}
\hline & \multicolumn{5}{|c|}{ Dependent variable } \\
\hline & $\begin{array}{l}\text { Fruit for } \\
\text { lunch }\end{array}$ & $\begin{array}{l}\text { Chips for } \\
\text { lunch }\end{array}$ & $\begin{array}{l}\text { Sweets for } \\
\text { lunch }\end{array}$ & $\begin{array}{c}\text { Healthy frequency } \\
\text { variable }\end{array}$ & $\begin{array}{c}\text { Unhealthy frequency } \\
\text { variable }\end{array}$ \\
\hline \multicolumn{6}{|l|}{ Sample size } \\
\hline Student $(n)$ & 5025 & 5021 & 5019 & 4996 & 4908 \\
\hline School $(n)$ & 64 & 64 & 64 & 64 & 64 \\
\hline \multicolumn{6}{|c|}{ School-level variance } \\
\hline Wald test & $11 \cdot 41$ & $13 \cdot 81$ & $8 \cdot 84$ & $10 \cdot 74$ & $6 \cdot 34$ \\
\hline$P$ value & $<0.01$ & $<0.01$ & $<0.01$ & $<0.01$ & 0.01 \\
\hline
\end{tabular}

Data were collected from secondary schools in Wales that were a part of the 2005/2006 Health Behaviour in School-aged Children (HBSC) study; the final sample for analysis included data from 6693 students aged 11-16 years and 289 teachers from sixty-four secondary schools in Wales.

Table 4 Percentage of school-level variance in dependent variables explained by levels of influence of the socioecological framework adopted by the present study

\begin{tabular}{|c|c|c|c|c|c|}
\hline & \multicolumn{5}{|c|}{ Dependent variable } \\
\hline & $\begin{array}{l}\text { Fruit for } \\
\text { lunch }\end{array}$ & $\begin{array}{l}\text { Chips for } \\
\text { lunch }\end{array}$ & $\begin{array}{l}\text { Sweets for } \\
\text { lunch }\end{array}$ & $\begin{array}{c}\text { Healthy frequency } \\
\text { variable }\end{array}$ & $\begin{array}{c}\text { Unhealthy frequency } \\
\text { variable }\end{array}$ \\
\hline Student demographic & 0.63 & 0.28 & 0.91 & 0.32 & 0.91 \\
\hline Student intrapersonal & $2 \cdot 64$ & $2 \cdot 08$ & $2 \cdot 01$ & $4 \cdot 45$ & $5 \cdot 87$ \\
\hline Student interpersonal & $19 \cdot 86$ & $17 \cdot 56$ & $25 \cdot 93$ & $2 \cdot 22$ & $2 \cdot 21$ \\
\hline School organisation & 3.98 & $6 \cdot 37$ & $12 \cdot 16$ & $6 \cdot 55$ & $11 \cdot 61$ \\
\hline School community & $3 \cdot 44$ & $4 \cdot 54$ & $4 \cdot 27$ & $8 \cdot 97$ & $4 \cdot 23$ \\
\hline Macro-level organisation & 0.41 & 0.08 & $<0.01$ & 0.01 & $1 \cdot 16$ \\
\hline Total model & $96 \cdot 35$ & $75 \cdot 80$ & $79 \cdot 94$ & $98 \cdot 19$ & $83 \cdot 88$ \\
\hline
\end{tabular}

Data were collected from secondary schools in Wales that were a part of the 2005/2006 Health Behaviour in School-aged Children (HBSC) study; the final sample for analysis included data from 6693 students aged 11-16 years and 289 teachers from sixty-four secondary schools in Wales.

subjects useful in learning about healthy eating' is representative of an individual's attitude towards the classroom education on healthy eating, this can influenced by the school approaches to health education, found at the school organisation level. These in turn will be influenced by the National Curriculum, found at the macro level. Indeed the macro level will influence many of the variables included in the analysis, such as the subjects within which schools teach healthy eating, the food served within the school and the students eligible for free school meals.

The only macro-level influence included in our SEM was school participation in the Welsh Network of Healthy School Schemes (WNHSS) which is a national initiative that demands schools undertake certain health promoting actions to be considered 'healthy' schools. Although macro-level factors will influence many of the factors at a number of levels of the SEM, differences between schools in these factors will only occur due to the extent the school adopts national policies or differences between local authorities in which schools are based. A means of measuring the association of public policies, therefore, is to measure how much schools adhere to these macrolevel factors, as was done in the present study through the number of phases schools had completed in the WNHSS.

A number of factors identified in the SEM developed for the present study were not included in the final analysis (Table 2). Ethnicity was not included as the student sample ( $n$ 7300) was mainly white British (94\%) and the low numbers for other ethnic groups were not large enough to make a statistical impact. Food preparation knowledge and skill along with family eating behaviour were not measured as a part of the HBSC within Wales, while schools did not report on links to parents in generating consistent messages around healthy eating or local authority approaches to school food. Local authorities were not included in the data collection.

\section{Amount of variance explained by levels of influence}

Multilevel analysis of the data allowed us to estimate the percentage of school-level variance in the dietary choices of students explained by the different levels of influence of the SEM (Table 4).

The variance explained by the total models was greater than the sum of the variance explained by each level for each dependent variable. This difference was greatest for the healthy sum variable for which the sum of the variance explained by each level was $22.9 \%$ of the variance explained by the total model; the difference was smallest for the sweets for lunch dependent variable for which the sum of the variance explained by each level was $56 \cdot 7 \%$ of the variance explained by the total model. 
Factors from the macro level explained the least amount of school-level variance for each dependent variable except for the unhealthy frequency variable, for which factors at the demographic level explained the least.

Factors at the student intrapersonal level explained more variance for the food frequency dependent variables, whereas student interpersonal factors explained more for the lunch dependent variables. School as an organisation explained more of the variance of the unhealthy food dependent variables (chips for lunch, sweets for lunch and the unhealthy frequency variable) than the factors at the school community level, which explained more of the variance for the healthy sum variable. The two school levels explained similar amounts of variance for the fruit for lunch variable.

\section{Discussion}

At the student level, student intrapersonal characteristics explained more of the variance for food eaten throughout the day than that eaten for lunch, while a greater proportion of the variance in lunch choices was explained by student interpersonal factors. At the school level organisational factors explained a greater proportion of variance in the dietary choice of unhealthy foods than community factors, which explained more of the variance in the dietary choice of food eaten throughout the day than those eaten for lunch only.

The main strength of the present study is that it had access to data from a large sample of secondary-school students from many schools within Wales. Using these data in multilevel analysis alongside those collected from teachers within the schools, analysis could be performed which incorporated a number of individual-level and school-level factors. By calculating the variance explained by variables from each level of the SEM for each dependent variable, the association between different levels of influence from the SEM and varied dietary choice could be studied.

The main limitation of the present study is that most of the variables come from self-report questionnaires. Both sets of dependent variables were derived from self-reported questions in the HBSC student survey. The sum variables came from the selected 'method of choice ${ }^{\text {(39) }}$ for the HBSC survey that has been validated ${ }^{(39)}$ while the lunch variables came from questions asking about the choice of specific foods for lunch ${ }^{(40)}$. Although these lunch variables came from a paper published in 1995 , leading to concerns about applicability to the reporting of current adolescent lunch behaviour, these were trialled in case studies prior to the data collection. The student-level independent variables all came from the HBSC survey and were self-report. Many of the school-level variables are crude, unvalidated measures, which are dependent upon teacher responses and provide no measure of quality for these actions. For both studentlevel and school-level variables, unless there is substantial variation across schools in reporting bias, this should not affect the estimated association in the models. The data for the present study are cross-sectional; as they are not longitudinal no causality can be inferred between levels of the SEM and the dependent variables, only a significant association can be derived.

Although other studies have developed conceptual models based on SEM for studying healthy eating in schools, none were found that investigated the relative association of these levels on the behaviour of students. Studies that have investigated the school effect on health behaviours, including healthy eating, using multilevel analysis found no significant school effect on student dietary choice once controlling for student-level characteristics ${ }^{(5,15,26,27)}$. The significant school-level variation on controlling for studentlevel factors and the amount of variance explained by school-level characteristics in the present study contradict these earlier findings. One explanation for this difference may be due to the greater school and student sample size within the present study. The largest sample size in previous multilevel studies identified by the authors was fifty-nine schools $^{(26)}$ and 3225 students $^{(5)}$ while the smallest was fifteen schools ${ }^{(27)}$ and 1293 students $^{(27)}$, compared with 6693 students in sixty-three schools included in the present study. We also built on previous multilevel studies in student dietary choice in schools ${ }^{(5,15,26,27)}$ by including more variables at both the student and school levels and by separating determinants operating at the different levels of the SEM to estimate the association they had with the reported dietary choice of students.

The small amount of between-school variance in the dependent variables attributed to factors at the student demographic level of influence highlight some differences between individuals of different ages and sexes which explained small amounts of school-level variance due to slight differences in ratios of students from different year groups and between sexes within the schools. A small percentage of schools were single sex.

The greater percentage of variance explained by the student interpersonal factors for the lunch variables than the food frequency variables highlights the association of norms of behaviour with lunch choices. As these are lunch choices made during the school day it would be expected that these reflect norms of peers with whom students eat lunch ${ }^{(41-43)}$; other interpersonal factors may be important, however, such as family norms ${ }^{(41,44,45)}$ and family setup ${ }^{(41)}$ and this finding would benefit from further investigation. The greater percentage of variance explained by the student intrapersonal factors for the sum variables than the lunch variables indicates the importance of the behaviour ${ }^{(41,46)}$ and attitude ${ }^{(47-50)}$ of individuals in dietary choices made throughout the whole day.

The greater percentage of variance explained by the school organisational factors, than those at the school community level, for all the unhealthy dependent variables may indicate the importance of school rules and policies ${ }^{(43,51-53)}$ on controlling unhealthy eating. It may 
be that these school rules and approaches are more effective at controlling unhealthy eating than they are at encouraging healthy eating. It must be recognised, however, that there was a greater number of variables in models from this level of influence (eleven variables) than for school community level (four variables); whereas the school community level explained a greater percentage of variance for the food frequency variables, highlighting the importance of the community environment ${ }^{(54,55)}$ in student dietary choices throughout the day.

Factors from the macro level were not found to explain a large amount of the variance in dietary choice, although this may be due to the fact that only one variable was included in models from this level of influence (number of phases school had completed as part of the WNHSS). Despite the relatively low variance explained by this level in comparison to other levels, the $1 \cdot 16 \%$ of the variance in unhealthy food choices made throughout the day explained by the number of phases schools had completed in the WNHSS indicates the association of this programme with student dietary choice. Larger studies comparing between local authorities, or even countries, may allow more factors at the macro level to be investigated.

The total variance explained by the final models was greater than the sum of the variances explained by each level of influence, highlighting the synergistic nature of these levels in influencing dietary choice, as proposed in the SEM. This supports the use of the SEM in investigating and developing school approaches to healthy eating. To develop this, further objective measurements of school and student actions would provide more confidence in the findings while a longitudinal approach would allow an inference of causality.

This model helps in both the targeting of interventions to promote behaviour change and in focusing research into approaches. This practice can be moved forward by using the SEM to identify which factors should be targeted in making schools more health promoting. The large amounts of variance explained by the student interpersonal level on reported lunch choices indicates the importance of social influences on student choices at lunch and the need for tackling social norms along with individual behaviour within schools. School approaches to food must involve both organisational and community aspects of the school, implementing policies and rules towards food and influencing the social networks within the school and between schools and the community.

\section{Acknowledgements}

The data collection was completed as part of a $\mathrm{PhD}$ funded by the Medical Research Council, UK; N.T.'s position at the University of Oxford is funded by the National Obesity Observatory. The PhD the data came from was undertaken at Cardiff University and was supervised by Professor Laurence Moore and Dr Simon Murphy. There are no conflicts of interest to report. N.T. was responsible for data collection, statistical analysis and writing the manuscript; he is the guarantor. C.F. contributed to the development of the study and provided critical review of the manuscript.

\section{References}

1. Pyle SA, Sharkey J, Yetter G et al. (2006) Fighting an epidemic: the role of schools in reducing childhood obesity. Psychol Sch 43, 361-376.

2. Ball K, Timperio A \& Crawford D (2006) Understanding environmental influences on nutrition and physical activity behaviors: where should we look and what should we count? Int J Behav Nutr Phys Act 3, 33.

3. Story M, Kaphingst KM \& French S (2006) The role of schools in obesity prevention. Future Child 16, 109-142.

4. Lister-Sharp D, Chapman S, Stewart-Brown S et al. (1999) Health promoting schools and health promotion in schools: two systematic reviews. Health Technol Assess 3, issue 22, 1-207.

5. Maes L \& Lievens J (2003) Can the school make a difference? A multilevel analysis of adolescent risk and health behaviour. Soc Sci Med 56, 517-529.

6. Bennett P \& Hodgson R (1992) Psychology and health promotion. In Health Promotion: Disciplines and Diversity, pp. 22-38 [R Bunton and G Macdonald, editors]. London: Routledge.

7. Macdonald G \& Bunton R (editors) (1992) Health promotion: discipline or disciplines? In Health Promotion: Disciplines and Diversity, pp. 6-21. London: Routledge.

8. Lynagh M, Schofield MJ \& Sanson-Fisher RW (1997) School health promotion programs over the past decade: a review of the smoking, alcohol and solar protection literature. Health Promot Int 12, 43-60.

9. Green LW \& Kreuter MW (1999) Health Promotion Planning: An Educational and Ecological Approach, 3rd ed. Mountain View, CA: Mayfield Publishing Co.

10. World Health Organization (1997) Promoting Health Through Schools. Report of a WHO Expert Committee on Comprehensive School Health Education and Promotion. WHO Technical Report Series no. 870. Geneva: WHO.

11. World Health Organization (2002) The Egmond Agenda: Establishing Health Promotion in Schools: Components for Success. Copenhagen: WHO Regional Office for Europe.

12. Dooris M (2009) Holistic and sustainable health improvement: the contribution of the settings-based approach to health promotion. Perspect Public Health 129, 29-36.

13. World Health Organization (1997) The Health Promoting School: An Investment in Education, Health and Democracy: Conference Report on the First Conference of the European Network of Health Promoting Schools, Thessaloniki, Greece. Copenhagen: WHO Regional Office for Europe.

14. Mũkoma W \& Flisher AJ (2004) Evaluations of health promoting schools: a review of nine studies. Health Promot Int 19, 357-368.

15. West P, Sweeting H \& Leyland A (2004) School effects on pupils' health behaviours: evidence in support of the health promoting school. Res Papers Educ 19, 261-291.

16. World Health Organization (1986) Ottawa Charter for Health Promotion. Geneva: WHO.

17. Stokols D (1996) Translating social ecological theory into guidelines for community health promotion. Am J Health Promot 10, 282-293.

18. Story M, Neumark-Sztainer D \& French S (2002) Individual and environmental influences on adolescent eating behaviors. J Am Diet Assoc 102, Suppl. 1, S40-S51. 
19. Story M, Kaphingst KM, Robinson-O'Brien R et al. (2008) Creating healthy food and eating environments: policy and environmental approaches. Annu Rev Public Health 29, 253-272.

20. Thomas J, Sutcliffe K, Harden A et al. (2003) Children and Healthy Eating: A Systematic Review of Barriers and Facilitators. London: EPPI-Centre, Social Science Research Unit, Institute of Education, University of London.

21. Wind M, Bjelland M, Pérez-Rodrigo C et al. (2008) Appreciation and implementation of a school-based intervention are associated with changes in fruit and vegetable intake in 10- to 13-year old schoolchildren - the Pro Children study. Health Educ Res 23, 997-1007.

22. King AC, Stokols D, Talen E et al. (2002) Theoretical approaches to the promotion of physical activity: forging a transdisciplinary paradigm. Am J Prev Med 23, Suppl. 1, 15-25.

23. Kumanyika S, Jeffery RW, Morabia A et al. (2002) Public Health Approaches to the Prevention of Obesity (PHAPO) Working Group of the International Obesity Task Force (IOTF). Obesity prevention: the case for action. Int J Obes Relat Metab Disord 93, 1168-1173.

24. Klepp KI, Pérez-Rodrigo C, De Bourdeaudhuij I et al. (2005) Promoting fruit and vegetable consumption among European schoolchildren: rationale, conceptualization and design of the Pro Children project. Ann Nutr Metab 49, 212-220.

25. Dzewaltowski DA, Estabrooks PA \& Johnston JA (2002) Healthy Youth Places promoting nutrition and physical activity. Health Educ Res 17, 541-551.

26. Krolner R, Due P, Rasmussen M et al. (2009) Does school environment affect 11-year-olds' fruit and vegetable intake in Denmark? Soc Sci Med 68, 1416-1424.

27. van der Horst K, Timperio A, Crawford D et al. (2008) The school food environment: associations with adolescent soft drink and snack consumption. Am J Prev Med 35, 217-223.

28. Townsend N, Murphy S \& Moore L (2011) The more schools do to promote healthy eating, the healthier the dietary choices by students. J Epidemiol Community Health 65, 889-895.

29. McLeroy KR, Bibeau D, Steckler A et al. (1988) An ecological perspective on health promotion programs. Health Educ Behav 15, 351-377.

30. Bronfenbrenner U (1979) The Ecology of Human Development. Cambridge, MA: Harvard University Press.

31. Bronfenbrenner U (1977) Toward an experimental ecology of human development. Am Psychol 32, 513-531.

32. Dahlgren G \& Whitehead M (1991) Policies and Strategies to Promote Social Equity in Health. Stockholm: Institute for Future Studies.

33. Barton $H \&$ \& Grant $M$ (2006) A health map for the local human habitat. J R Soc Promot Health 126, 252-253.

34. Currie C, Samdal O, Boyce et al. (2002) Research Protocol for the 2001/2002 Survey. Edinburgh: HBSC.

35. Story M, Giles-Corti B, Yaroch AL et al. (2009) Work Group IV: future directions for measures of the food and physical activity environments. Am J Prev Med 36, Suppl. 1, S182-S188.

36. Sellström E \& Bremberg S (2006) Is there a 'school effect' on pupil outcomes? A review of multilevel studies. J Epidemiol Community Health 60, 149-155.

37. Rasbash J, Steele F, Browne W et al. (2004) A User's Guide to MLwiN. Bristol: Centre for Multilevel Modelling, University of Bristol.
38. Hox J (2002) Multilevel Analysis Techniques and Applications. London: Lawrence Erlbaum Associates.

39. HBSC (2002) Overview: Health Behaviour in School-aged Children. http://www.hbsc.org/overview.html (accessed February 2008).

40. Dennison CM \& Shepherd R (1995) Adolescent food choice: an application of the Theory of Planned Behaviour. J Hum Nutr Diet 8, 9-23.

41. Rasmussen M, Krølner R, Klepp K-I et al. (2006) Determinants of fruit and vegetable consumption among children and adolescents: a review of the literature. Part I: quantitative studies. Int J Behav Nutr Phys Act 3, 22.

42. Kalavana TV, Maes S \& De Gucht V (2010) Interpersonal and self-regulation determinants of healthy and unhealthy eating behavior in adolescents. $J$ Health Psychol 15, 44-52.

43. Neumark-Sztainer D, Wall M, Perry C et al. (2003) Correlates of fruit and vegetable intake among adolescents. Findings from Project EAT. Prev Med 37, 198-208.

44. Perez-Pastor EM, Metcalf BS, Hosking J et al. (2009) Assortative weight gain in mother-daughter and father-son pairs: an emerging source of childhood obesity. Longitudinal study of trios (EarlyBird 43). Int J Obes (Lond) 33, $727-735$

45. Pearson N, Biddle SJH \& Gorely T (2009) Family correlates of fruit and vegetable consumption in children and adolescents: a systematic review. Public Health Nutr 12, 267-283.

46. Giovannini M, Agostoni C \& Shamir R (2010) Symposium overview: do we all eat breakfast and is it important? Crit Rev Food Sci Nutr 50, 97-99.

47. Martens MK, van Assema P \& Brug J (2005) Why do adolescents eat what they eat? Personal and social environmental predictors of fruit, snack and breakfast consumption among 12-14-year-old Dutch students. Public Health Nutr 8, 1258-1265.

48. Nutbeam D, Smith C, Moore L et al. (1993) Warning! schools can damage your health: alienation from school and its impact on health behaviour. J Paediatr Child Health 29, Suppl. 1, S25-S30.

49. Brug J (2008) Determinants of healthy eating: motivation, abilities and environmental opportunities. Fam Pract 25, Suppl. 1, i50-i55.

50. Kann L, Telljohann SK \& Wooley SF (2007) Health education: results from the School Health Policies and Programs Study 2006. J Sch Health 77, 408-434.

51. Nelson M, Bradbury J, Poulter J et al. (2004) School Meals in Secondary Schools in England. London: King's College London, National Centre for Social Research, Nutrition works!.

52. Kubik MY, Lytle LA, Hannan PJ et al. (2003) The association of the school food environment with dietary behaviors of young adolescents. Am J Public Health 93, 1168-1173.

53. Neumark-Sztainer D, French SA, Hannan PJ et al. (2005) School lunch and snacking patterns among high school students: associations with school food environment and policies. Int J Behav Nutr Phys Act 2, 14.

54. Gould R, Russell J \& Barker ME (2006) School lunch menus and 11 to 12 year old children's food choice in three secondary schools in England-are the nutritional standards being met? Appetite 46, 86-92.

55. Resnicow K, Davis-Hearn M, Smith M et al. (1997) Socialcognitive predictors of fruit and vegetable intake in children. Health Psychol 16, 272-276. 